\title{
Folk in Opposition? Wedding Bands and the New Developments in Bulgarian Popular Music
}

\author{
CLAIRE LEVY \\ Translated by Katia McClain and Claire Levy
}

\section{Introduction}

The following is an excerpt from my recently published book Etnodžazat: lokalni proekcii $v$ globalnoto selo [Ethnojazz: local projections in the global village] (Sofia: BAN_-Institut za izkustvoznanie, 2007). Devoted to the idea of ethnojazz as an innovative form of interaction between Bulgarian/Balkan folk and a global jazz vocabulary, the book discusses the music of emblematic artists from different genre backgrounds, who articulate a new development in music and a new horizon in the mixing of musical languages. Such musicians introduce a specific artistic awareness, which goes beyond blank mimicry in the appropriation of traditionally-oriented ideas concerning the jazz idiom. Not accidentally, their common line, defined by Western critics as "Bulgarian exceptionalism," is dominated and stimulated by the Balkan wedding-band tradition, which is now moving in new musical directions that are difficult to define under established musical labels. Perhaps this is why this genre is so distinct and thrilling.

The excerpt draws attention to the controversial attitudes toward the wedding band boom in the 1980s and its significant impact in the following decades on both the dominant Bulgarian sound environment and those innovative forms of jazz fusions, spiced with a tangible Balkan flavor. Seen from the perspective of drugata narodna muzika (the other folk music), wedding bands are a melting pot of multi-ethnic vernacular traditions. By drawing away from the concept of folk purism, an ideology essential for national politics and the dominant culture during the socialist period in Bulgaria, wedding music opposes the romantic understanding of folk music as a pure tradition and brings forward the notion of a particular underground genre that freely encourages the involvement of a variety of "foreignisms" in the Bulgarian musical lexicon. This opposition perspective is further developed in relation to the process of self-identification among contemporary folk musicians who personify an updated artistic model that is identical neither to the aesthetics of the State-promoted folk ensembles nor to the museum-like idea of preserving traditions. My key thesis focuses on the understanding of a neofolk perspective that abandons the claim of "art" as an autonomous object, and embraces the essence of folk as a specific cultural field in the modern world, open to unpredictable paths of artistic freedom. I argue that today's folk musicians experience a new wave of creativity and freedom in reappropriating the "two sides of the coin," as if to revive the syncretism of that artistic behavior which, in jazz as well as in folk, does not divide musicians into composers and performers but makes them full masters of the process of music-making.

\section{Returning to the self-other or about the other folk music}

In 1995, when the American magazine Newsweek declared that the Bulgarian master kaval ${ }^{1}$ player Theodosii Spassov had created a new musical genre that was seen as representing a particular direction in the field of contemporary jazz, the dominant soundscape in Bulgaria was already showing signs of a revitalized tradition in local vernacular music. Musicians drew freely on the tangled regional skein of local Balkan roots,

\footnotetext{
${ }^{1}$ A wooden rim-blown flute played in traditional Bulgarian village folk music.
} 
but also from a wide spectrum of globalized sounds projected onto the field of contemporary popular music. At approximately the same time, astounded Westerners were struck by the whirlwind tempi, complex metric and rhythmic patterns, passionate tunes and unusual (for the Western ear) timbres and modal structures heard beyond the Balkans as early as the eighties - say, for example, in the playing of Ivo Papasov ${ }^{2}$ and his orchestra Trakia. ${ }^{3}$ The West had begun to talk about the legendary performers of Bulgarian wedding music, described as a new phenomenon that "in the 1980s transformed the East-European musical terrain with its mighty blend, woven from Balkan folk, spiced with jazz, rock, Gypsy, Turkish, and Indian music."4

There is no doubt that the Western world had noticed the alternative impulses in the new ethnomusic from Bulgaria, touched as if by the wild blast and somehow irrational waft coming from those zones which, in the words of Richard Middleton, were formally abused but subconsciously desired in post-Renaissance Europe (see Middleton 2000, 61). Connected mainly to the traditions of rural folk and urban vernacular music, such zones remind us in a particular way of the Other in Europe, as well as of that "Dionysian" sensitivity presently observed in the ubiquitous mosaic of non-standard phenomena teeming along unknown paths in the variegated context of the global postmodern situation.

At the end of the twentieth century, it appears that the West, shedding layered taboos and simplifying cultural interpretations, is looking for new stimuli in the notions of "roots" and "authenticity." Weariness with the mimicry of rational and somehow sterile strategies in the creation of musical artifacts or boredom with the slick brilliance of the refined expression of pop culture has activated a taste for difference, for those not quite known but inspiring cultural spaces connected with the symbolic and enigmatic nature of regional traditions that ignite the imagination, although not always at a conscious level. Even the growing global interest in the peculiar literary world of Marquez ${ }^{5}$ and Radičkov ${ }^{6}$ or in the non-standard musical journeys of Ibrahim Ferrer, Ivo Papasov, Boban Marković and Goran Bregović can be seen as symptomatic. Apparently, the Western world has become more curious about the characteristic energies of regional cultures. Similar attitudes, it seems, are unfolding under that logic of general cultural processes which gave rise to such transborder phenomena as, say, world music. ${ }^{7}$

The global craze for regional cultures created new prospects for the already innovative sounds of Bulgarian wedding music. Fitting, in a sense, the famous postmodern motto "Think globally, act locally!," it is these sounds that feed, to a great degree, the contours of the new wave in Bulgarian jazz, as well as coloring other non-traditional genre trends in the field of Bulgarian popular music that emerged in the beginning of the 1990s.

It is worth noting, however, that the flourishing of local ethnomusic, based strongly on multi-ethnic fusions between regional Balkan sounds, was perceived at that time as a peculiar novelty in the soundspace, not only by Westerners but also by Bulgarians. The paradoxes in the dynamic between concepts of "self" and "other" had pushed identification processes in such a way that, at the end of the 1980s, the sound profile of

\footnotetext{
${ }^{2}$ Bulgarian master clarinetist of Turkish-Rom origins, innovator of local wedding music.

${ }^{3}$ Papasov formed Trakia in 1974. Joe Boyd, producer of the albums Orpheus Ascending (1989) and Balkanology (1991), had a fundamental role in the popularization of Ivo Papasov and Trakia outside Bulgaria. The albums were issued by the British company Hannibal Records.

${ }^{4}$ Adapted from Carol Silverman's publicity notes for the US tour of Yuri Yunakov, Ivo Papazov, Salif Ali and Neško Nešev and from their album Together Again, issued in 2005 by the American record company Traditional Crossroads, which specializes in world music.

${ }^{5}$ Gabriel García Márquez, Columbian Nobel-prize winning novelist noted for his style of magical realism.

${ }^{6}$ Jordan Radičkov (1929-2004), influential Bulgarian writer who also wrote novels infused with magical realism.

${ }^{7}$ Although world music is sometimes realized as a condescending nod of the modern West to the "exotic" nature of its "Others," it is a phenomenon that hints in a particular way at the decline of the "big narratives" and the upsurge of "small" ones. Placing fragments of heterogeneous musical traditions in new relations with global popular culture, the trend of world music proves to be a chance for non-Western musicians to be noticed outside their regional environments and to be included more effectively among the most recent phenomena in the world of contemporary music (see Levy 2005).
} 
popular music within Bulgaria - at least the one that dominated the public media space and influenced an essential part of the Bulgarian musical mainstream - was related more to the vocabulary of a pro-Western oriented, modernizing sound lexicon than to the traditional vernacular language of the local self. Despite ideological restrictions, the result of centralized cultural politics that ran for nearly half a century, the leading trends in the development of pop, rock and jazz in Bulgaria during the 1960s, 1970s, and 1980s revealed an insatiable striving toward the acquisition of just such modernizing intonational orientations. In a sense, the view toward dynamically changing global fads prompted tendencies that reformulated local concepts of "everyday music," especially those which had a bearing on the attitudes and preferences of the generations formed in the context of urbanized Bulgaria during the second half of the twentieth century. In this way the local self, understood as a polyphonic set that ranged over musical traditions of different local ethnic communities, was for a long time pushed out to the periphery of the public space, mostly because of its Balkan flavor and of complicated sociopsychological connotations dominated by negative signs and the allusion of "backwardness" (see Levy 2004).

On the other hand, the specific profile of folk music disseminated by the media, connected mainly to the institutionally encouraged "museum-like" or beautified and magnificently staged "concert" representations of Bulgarian folklore in the years after the Second World War, had distanced folk music from the expectations of a living and naturally functioning, naturally developing vernacular folk music with roots in local traditions.

Gencho Gajtandžiev reflects on the character of the second, concert trend, marked by glossy stylistics in the spirit of the western Music Hall and a somehow distanced artistic vision that is intended for the "big stage:" "Is there any truly 'folk' idea in the stage costumes, stylized more and more richly by famous artists and designers, in the songs arranged by professional composers, and in the glittering expensive panels in the folk style that cover the walls of the houses of culture?" (Gajtandžiev 1990, 126). The author alludes to the predominantly ostentatious profile associated with the common practices of the state folk ensembles and sees the reasons for their alienation from "the music of everyday life" as a reflection of the widely represented view, sustained among some influential folklorists and academically oriented musical spheres, “. . . of the incompatibility between musical folklore and current pop and rock music” (Gajtandžiev 1990, 120).

On the other hand, Gajtandžiev does not fail to note the suspensory role of the long-cultivated romantic concept of preserving the "purity" of Bulgarian folklore. ${ }^{8}$ Contrary to this concept, Gajtandžiev argues that folklore is a living organism and that musical traditions may be protected only by means of their constant renewal: "Do we realize that the folkloric legacy, like an organic whole, like a vital system . . is part of a way of life, . . .which remains irreversibly in the history, the museums, the memories, the genetic code of a community?" (ibid).

Directing our attention toward folk as a process, such a point of view brings with it a particular perspective. Although already distant from the semantics of the ritual-ceremonial tradition, the folk idiomatic, felt now more as a convention for a given artistic expressiveness, finds its place in the contemporary world. The most natural environment in this regard is the non-formalized sphere of life, long neglected in the public space of the Bulgarian situation. This is especially true for those of its niches in which the link between the intimate and communal experience is difficult to subject to external sanctions or forms of centralized control. Such a niche in the Bulgarian case turns out to be the peculiar cultural territory of the village wedding, a space in which, during the 1970s and 1980s, the sentiment toward folkloric tradition lived in the context of changed current conditions. Split between "past" and "present," between "traditional" and

\footnotetext{
${ }^{8}$ Recurrences of this trend glimmer forth even today in a number of public statements. M. Todorov, for example, passionately continues to argue for the proclamation of "a law for the preservation of the purity of Bulgarian folklore." See Sarandilčev, 2005.
} 
"modern," between "rural" and "urban," the cultural space of the village wedding outlines a new stage in the inescapable process of modernization, as well as in the revitalized contours of that eclectic feeling for semirural-semiurban living that to a certain degree has accompanied Bulgarian culture at least from the time of Diko Iliev. ${ }^{9}$

In this sense, the wedding orchestras' boom during the 1980s is not accidental. The existing vacuum in the sphere of locally-oriented vernacular music as well as the new sociocultural situation stimulated liberating impulses in the function of folk music, defined at that time usually as "wrong" and "distorted." It is also not accidental that wedding playing, that other folk music, is realized as a kind of underground - that is, as a tendency that has turned from the orthodox, from the "right" path, and from hidebound notions of the preservation of the folkloric heritage. Formed under the strong impact of the romantic idea concerning the existence of "pure" folklore, the Bulgarian, eager-to-become-modern and Westernized, correlates weddingmusic more with the concept of some kind of local "home-grown" exotic, understood in conjunction with the valued marks of cultural backwardness and ignorant primitivism. Even during the 1990s, when the dominant notions in the wide vernacular sphere and the already partially deregulated media space were largely influenced by the intonations and innovative artistic approach developed in wedding music, the majority continued to perceive the characteristic accents of this updated Balkan expressivity, rich as it was in specific and generous intonations of "Eastern" sensuality, as a "foreignism" in the vocabulary of Bulgarian music.

In a sense such an attitude is a reflection of public polemics, still undertaken "from above" in the mid1980 s, on the countenance of wedding music, which at that time was experiencing a powerful new development. The proponents of these public polemics criticized the "anarchism" that had swept through the folk instrumental tradition, that is, an artistic freedom sublimating a set of spontaneously arising innovations including a line of ostentatious, uncontainable virtuosity and improvisational approaches that crossed ethnodialects from different regions and also fused intonations with a far from local origin. In the words of Gajtandžiev, "arguments of a different nature are adduced in defense of a quite extreme, generalizing and completely non-pluralistic view, which might be summarized thus: these ensembles and the music that they spread . . . distort and debase folklore, because of which they occupy an undeserved place in the sphere of contemporary musical culture. And this is why, in order to exist in the future, they must 'cleanse' their music and place their production inside 'prescribed boundaries'." (Gajtandžiev 1990, 128).

The call for the "cleansing" of "foreign" elements from wedding music by means of the exercise of a central control manifested itself in various ways. The intention to sanitize this type of music, to do away with the "warped" in relation to notions of the "right" folk music, projected itself finally into the sanctioned politics of specialized juries for the selection of groups for participation in the State-initiated national review of instrumental folk music ensembles that took place in Stambolovo in the mid 1980s. The idea of obliterating the "foreignisms" that characterized the capricious nature of this musical practice and which had assumed exceptional dimensions in the field of non-formalized music-making (especially in the territory of the village wedding), was declared more than once in different public forums. In the words of the chair of the jury, the aim was "to preserve authentic folk tunes in a manner attractive to young people," but "the other goal of the festival, Todorov ${ }^{10}$ said frankly, was to eliminate foreign elements from our neighbors in the music" (Rice 1994, 255).

Nearly twenty years after the first festival in Stambolovo, Gajtandžiev states that Todorov (the chair of the jury at Stambolovo) continues to act as "the father of wedding orchestras." Gajtandžiev does not refrain from commenting with irony: “. . . from the screen of a television I caught the familiar voice of the venerable

\footnotetext{
${ }^{9}$ Well-known Bulgarian musician and composer (1898-1985), who based his compositions on motifs from the folk music of Northwest Bulgaria. One of his most famous pieces is Dunavsko horo.

${ }^{10}$ Manol Todorov was a musicologist and professor of music at the Sofia Conservatory (Rice 1994, 251).
} 
professor. I peered at the television set - it was indeed him! The host, much younger than him, addressed him with respect for his rank as 'the father of wedding orchestras.' And I, who really love to dig around in the family ties of individuals, was suddenly struck by whose son Ivo Papazov must really be! Then the professor eloquently explained what effort it had cost him to direct, cultivate, cleanse, put on the correct path, and dress up the "chalgadjii" ${ }^{11}$ so that they might fit into the 'correct' Procrustean bed that he had set for them. Then he expressed his indignation that some singers (female and male) have the insolence to try to compose a song themselves, without having studied composition for three years ..." (Gajtandžiev 2000, 5).

The comments of American ethnomusicologist Timothy Rice, an expert and researcher of long standing on Bulgarian folk music, are curious in this regard. Rice noted the dual behavior of the musicians during the reviews in Stambolovo (see Rice 1994, 253). Describing his observations during the festival in 1988, the author directs our attention to a peculiar trick in the behavior of the orchestras, which practiced a double standard in presentation: one "right," when in front of the jury; the other free, when in front of the people. The latter style is dedicated to the unpredictable movements of virtuoso improvisation that involve the given conventions only as a prop and a moment in the building of music that flows, exactly like a club jam session, according to the caprices of the situational logic. The "right" way of playing is pro-forma, something that can secure a "passport" for the musicians to the Stambolovo festival stage, where the audience of many thousands, without a doubt, has flocked to hear the second, "incorrect" playing, which had acquired the aura of a kind of defiance and was a trade-mark of wedding music.

In his description, Rice also points out fundamental stylistic differences between the two types of playing, which are construed as a manifestation of a certain aesthetic profile. The author connects one tendency, encouraged by the jury, with stylistics marked by moderate volume, moderate tempi, tight rhythmic and melodic unisons, all subordinated to the idea of a "sweet" (that is, prettified or saccharine) sound. The melodies and improvisational moments, although they might include elements of contemporary wedding music (for example, chromaticisms and arpeggios) are restricted to four- and eight-bar phrases. This mode of playing reveals a type of self-control and self-discipline, cultivated to a large degree according to delineated notions of folk music, influenced by the aesthetic of Western-oriented models, and by standards connected to what might be called "radio-stylistics," which form a substantial part of folkloric music intended for media broadcast.

The other tendency, the antithesis to radio-stylistics and to controlled playing, reveals an approach, described most often by the expert members of the juries as "irritatingly aggressive" (and yet especially liked by the audience!). The sound here is "non-sweet" (that is, natural, non-saccharine), notable for sharper and louder acoustic characteristics, and for taking the path of unfettered improvisational music-making. This approach exploits the sound and technical potential of the instruments to the utmost limit, breaking the conventional four- and eight-bar structures and changing the harmonies in an unpredictable way. Usually, each performance on the stage in Stambolovo lasted around twenty minutes. Leading off most often with a song melody in a danceable tempo followed by a series of instrumental dance tunes typical of a given region, the musicians would then move into improvisations, breaking the model of the customary "radio" arrangements and finding their way by this means to the real stylistics of wedding music. In his description Rice also emphasizes that "some groups, particularly those that played for Gypsy and Turkish weddings, dispensed with the sweet aesthetic all together and played with $h \breve{u} s,{ }^{12}$ from the beginning of their performance to the end" (Rice 1994, 253).

\footnotetext{
${ }^{11}$ Chalgadjija: a musician who represents the Balkan vernacular instrumental tradition named "chalgija" (from the Turkish word chal, meaning "play").

12 "With gusto," “[ . . . from a Turkish word, hiz, meaning 'speed, velocity, rush, impetus, dash, elan' (Redhouse 1968)]" (cited in Rice 1994, 248).
} 
According to Rice, the two approaches might also be construed as a manifestation of different aesthetic views of the tradition: one connected more to the "Bulgarian" point of view; the other to the "Rom" attitude in music-making. As to the interpretation of the second, "aggressive" tendency as also a metaphor for certain oppositional meanings, the mere circumstance that it is precisely understood as a threat to some kind of status quo and that it becomes a reason for undertaking sanctioning measures is certainly an argument in support of the view that a particular "folk in opposition" has emerged in the context of Bulgarian folk music. The attempt at control in relation to this style in wedding music-making is revealed even in acts that, at first glance, have as their goal the popularization of musicians like Ivo Papasov. For example, the album of wedding playing by this master-musician and renowned clarinetist issued by Balkanton ${ }^{13}$ at the end of the 1980 s is nothing more than a flirtation with his name. There is not even a trace in the album of the "aggressive" tendency that originally developed as a result of Papazov's innovative playing. On the contrary. Produced in the spirit of "correct" folk music, the recordings here have had the stylistics characteristic of "real" wedding music-making surgically removed. The improvised moments are reduced to a minimum, the general sound more closely resembles that of the moderate, encouraged "from above," controlled radiostylistics.

Not accidentally defined as "dissident" (Kaufman 1995) or "rebellious" (Levy 2000), this particular "folk in opposition" reveals the course of irreversible processes - as well as, by the way, the potential of liberating an artistic self-awareness for which it is difficult to claim that it simply reproduces "premodern" archetypes or antediluvian notions of traditional "rural" music. And if the revival of the self-other-or, in other words, the return to the self-but-already-other - starts from the boom of wedding orchestras, the subsequent reflections of this development reach a far wider genre zone. Observed in the revitalized, locallycolored modifications of the concepts of pop, rock and jazz, these reflections touch far more than just the non-standard folkjazz kaval of Theodosii Spassov, the vocal experiments of Yildiz Ibrahimova (Balkanatolia 1997), the jazz compositions of the group Zig Zag Trio (Ralchev-Yuseinov-Yankulov) (When The Bees Are Gathering Honey 2000), or of the ensemble Bulgara (Bear's Wedding 2005). They stretch to the episodic folk-interpretations of rock musicians like, for example, the young men of Er malŭk (Bŭlgari 1992) and the group Control (1991), as well as to the funny cover-versions of emblematic pop and rock hits interpreted "in the Gypsy manner" by Gypsy Aver (1993-4). Looking still more widely, such reflections also dominate in the growing repertoire connected with the festival "Pirin folk" (that started with an original orientation mainly toward the Macedonian folkloric dialects), in the ensuing "orientalization" of increasing numbers of pop-folk singers and instrumentalists in the 1990s, and in the artistic attitudes sublimated in the dimensions of polysemic fusion presented, for example, by ensembles like Cuckoo Band.

The wedding orchestras initiate characteristic nuances of a current, topical intonational milieu that combines the essence of at least two lines, two continuities, two sociocultural logics, all seemingly incompatible or at least independent of each other. Viewed historically, these two lines are at first glance in opposition to each other, as they embody respectively concepts of a tie with "premodern" and "postmodern" attitudes in cultural self-awareness. The one line, understood as "premodern," we perceive in the dynamics of Balkan folk, especially as it relates to developments in those of its parts whose roots lead toward the tradition in vernacular playing known as chalgija ${ }^{14}$ - a tradition which, at least from the middle of the nineteenth century, is connected with the prolonged, specifically Balkan transition from a rural to an urban way of life. The other line, which arose in the postmodern context of Western culture, leads toward the cosmopolitan

\footnotetext{
${ }^{13}$ The Bulgarian State Record Company, established in 1952.

${ }^{14}$ It is worth noting that the tradition of chalgija, developed originally mostly by traveling musicians of Gypsy and Jewish origin, also stands at the foundation of the music designated with the name Klezmer, one of the widely discerned folk musical trends of the twentieth century Jewish Diaspora.
} 
profile of the phenomenon world music. Although an offspring of Western pop culture, world music turns out to be one of the paradoxical stimuli in the turn toward the "local other," which plays the role of a valued mirror, the role of the other, of the "external" view. The global mode of the folk-revival, sublimated in the amorphous nature of world music, inspires new, prestigious connotations vis-à-vis the semantics of regional vernacular vocabularies of various origins, including also those of a pan-Balkan lexical stock that had entered the vernacular traditions of the Balkan cultures. As Gajtandžiev notes, no one is a prophet in his or her own place: "Life had to impose its own demands in order to correct some stereotypes, in order to reassess familiar views . . . and maybe it really was necessary for the Misterijata na bălgarskite glasove [The Mystery of the Bulgarian Voices $]^{15}$ to intrude into the British pop charts, for the Trio Bŭlgarka to be photographed with George Harrison, for Joe Boyd, Kate Bush and others of their compatriots to display an interest in our folklore and, mainly, in the possibility that it might be successfully 'implanted' in one or another style of popular music, in order to change the public atmosphere . . ." (Gajtandžiev 1990,122). And there is something else. Such an examination through the eyes of the "other" stimulates that possibility of drawing nearer in the modern world, which in a series of relations correlates and connects the creative energies of subjects from different geographic and cultural zones in the direction of certain tendencies in music, as well as of a kind of musical cosmopolitanism. The chances of intercultural communication break the notions of "self" and "other," and connect subjects with otherwise heterogeneous national, ethnic, social, etc., selfconsciousnesses in common musical movements.

Regardless of the way in which we look for the motivations for the revival of the local self, the phenomenon undoubtedly renews the link and dialog with "memory," with that aspect of Bulgarian musical culture that acknowledges the tangled skein of its Balkan origins. And although "it is always possible to find someone, most probably by inertia, to rail at and abuse this memory as a dangerous destroyer of good manners, of 'good' taste, and of the 'purity' of Bulgarian music" (Gajtandžiev 2000, 5), the phenomenon also questions traditional social-psychological attitudes concerning "Bulgarianess," understood as a flat ideolgeme or as a frozen, static, non-dynamic category.

The revitalized intonational environment that took shape during the 1990s integrates the experience of different local ethnoses and unfolds beyond the concept of an isolated music of a defined minority group. In this sense it does not carry the marks of some narrowly differentiated ethnic or socially determined affiliation. Premised to a certain extent by the new sociocultural situation, which had liberalized Bulgarian culture in terms of a more apparent legitimization of minority ethnic groups, it acquires characteristics of an "omnipresent mark," and in reality places its stamp over diverse spaces inhabited by heterogeneous social communities.

It is said that every new thing is nothing other than a well-forgotten old one, hidden in the recesses of community memory, expecting to be awakened when the present summons it. This assertion illustrates the theory of the cyclical development of cultural processes. But in its metaphorical sense it also refers to an understanding that the world is as big as it is small, that time is as long as it is short, that the cultural phenomena emerging here and there are as unique as they are similar, and that the eternal exchange of cultural information forward and backward in time is at the root of "the new old phenomena." Taken in

\footnotetext{
${ }^{15}$ Usually known by its French name, Les mystères des voix Bulgares. This was the name given to the Bulgarian State Radio and Television Female Vocal Choir (founded in 1952), by Marcel Cellier, Swiss record producer, when he released the choir's first album in the West in 1975.
} 
relation to the processes of ethnomusic, this view illustrates the logic and dynamic of the resignification of the past-insofar as the "ethnic" presumes already existing experience, differentiated group memory, and sublimated syntheses in the music-making of a given community. But does the panorama of the "new old phenomena" at the end of the twentieth century hint at nostalgic attitudes? Or does it signify that the tradition-modern relation somehow revives in perspective - in a way connected with accumulations in terms of values and meanings that culminate in what some Western ethnomusicologists define as post-peasant folk movements (see Slobin 1993, 68), but which Bulgarian scholarship habitually defines with the term urban folklore? Do similar phenomena formulate the contours of a particular neofolkloric development, motivated this time from an essentially pluralistic vision with regard to its "roots," a vision that hints toward a consciousness of the flexible diversity of community traditions and their natural and inevitable interweaving?

In the mid 1990s the Bulgarian folklorist Todor Ivanov Živkov already spoke in more complex ways about revitalizing processes in the sphere of wedding music and of a notable folkloric boom that had seized different levels of Bulgarian popular culture. Živkov emphasized that the phenomenon "turns upside down concepts of folklore as an antique and places under question all hurried predictions of the collapse of Bulgarian culture" (Živkov 1994, 6). It is not accidental that he further points out that the "polyphonic nature of folkloric culture in Bulgaria," premised on the diversity of musical traditions and developed in the context of all ethnic communities, "is establishing itself more and more." Awareness of this polyphonic nature, asserts the author, is sublimated in something that "both carries new rhythms, and returns us toward familiar emotions ... and forms flashes of a new culture ... The folkloric boom makes our culture natural and vital .

. . It is a fruit of this time and we would err if we rush to brand it, to condemn its forms and manifestations with old-fashioned stigmas. It does not reject the old classical folklore. And it interprets it better than we do. It traces the paths of a new folkloric culture, for which we do not yet have categories, but toward which we have an inner attitude ..." (ibid). Arguing the thesis of folklore as a changeable need, the author at the same time casts a bridge toward the insight uttered decades earlier by the Bulgarian folklorist Rajna Kacarova, who acknowledged the view that "influences of a most diverse origin echo in the musical and dance heritage of the Bulgarian people ..." (Kacarova 1967, 61).

We cannot understand the nuances in the concept of the local "neofolklorism" if we do not grasp those transformational aspects in the contemporary cultural situation that direct our attention to the new character of the folk musician, combining elements of ritual-ceremonial functions (the wedding) with modern attitudes regarding the creation of music.

\section{The (Neo)folkloric player}

Why do I make reference to the player? What personifies his figure? Why exactly does he find a home at the core of today's Balkan ethnowave and why is he a crucial factor in its tangible unfolding? Viewed historically and in the social-psychological plan, is it not folk singing rather than folkloric instrumental music that from time immemorial has dominated public attention? Besides, the domination of song reminds us of the connection of folklore with the idea of the "natural." In contrast to the human voice, the musical instrument is not "nature itself," is not "a part of the body although, at least in the context of traditional folkloric culture, instrumental sound, besides a connection with 'ritual-material symbolism,' also carries a 'corporeal tie"' (Zaharieva 1987, 11).

As Svetlana Zaharieva points out, the process of "detachment from the object-symbolic nature of the instrument and a concentration on its acoustic-artistic features" is a recent phenomenon, connected to the transition to the modern era. This process is associated with the differentiation of music as an autonomous art, and with the gradual breaking down of folklore as a ritual-ceremonial system. Although not focusing 
especially on this problem, which she views as an aspect of the correlation between folklore and modernity, the author hints that this "newer cultural-historical variant of the musical player is an artistic creator of a modern type. This type, which begins to form during the breakdown of the traditional system . . . uses musical tradition as an artistic heritage, as a repertoire performed in a new, non-folkloric situation . . ." (Zaharieva 1987, 17-18). In this sense "the rules of instrumental music follow their own internal logic of development, in which the artistic tendencies toward self-development of the sound material appear ever more strikingly. This leads to the formation of an independent, purely musical expression . .." (Zaharieva 1987, 119). According to Zaharieva, "regardless of what this instrumentalist plays (authentic folklore or arrangements of non-folkloric music), he already lives with a new self-confidence (concert-performer's or even in some cases composer's). Such a performer, even when playing folk music, is no longer the offspring of the folkloric tradition, is not its creator and bearer. He is the product of a contemporary, complicated and 'polystylistic' musical-cultural situation, which is far from the folkloric tradition" (ibid, 17-18). On the other hand, notes the author, "the living tradition never carries only its external form, but preserves the memory of a deep meaning: the myth breaks through the artistic fantasy, the archetype becomes an aesthetic model, but the tradition carries in itself the emotional memory of the ancient, the awful, of the collective-incorporating" (ibid, 46).

Zaharieva understands the new role of the folk-player in the light of a predominant direction in the context of modernity. Her reflections elucidate mainly the aesthetic orientation of the folk ensembles created during the second half of the twentieth century. But how, in the case of such a formulation, are we to understand that "in-between" phenomenon that we designate with the term urban folklore? Can we insert the concept of the music of wedding players into the framework of categories like "concert music-making," "performer" and, only by exception, "author?"

Today's folk-player obviously actualizes that model of artistic behavior which enters into neither the aesthetics of the folklore ensembles nor the museum-like idea of preserving tradition. This model gives up the pretensions of the "artistic," understood as an alienated category, and turns toward the "folkloric," not simply in order to interpret it but to hold on to the essence of its nature. Today's player creates music, but does not live as a composer; plays on the concert stage, but does not need the inherent distance between musicians and public of concert music-making; plays for weddings, but is not confined to the zone of ritualceremonial music; guards the "memory," but does not see it as a frozen relic of the past. Music-making for him is woven into the idea of community life and is directed toward that mutuality in communication that integrates musical activity in a common, all-embracing field.

It is precisely in this idea that we notice reasons for acknowledgment not simply of a given genre trend, but of the formation of a new cultural-historical phase. It might be something different, something which is entered neither in traditional notions of concert music-making nor in left-behind models of a traditional folkloric type. But we may sense in it, as in classical forms of jazz, that particular synthesis between "premodern" and "modern" that is a synthesis between different types of cultures, symptomatically marked by a yearning for shared, "community" life.

Can we then look at today's player as a bearer of tradition? Can he be its creator? Indeed, it would certainly be closer to the truth to accept the fact that the neofolkloric musician actually does not merely carry the tradition. He is the tradition. For him folk is not "past," is not nostalgia, is not a museum. For him folk resides in the present. Intruding by non-traditional means into the notions of traditional music, the player today introduces new, actualized touches into the dynamic of that ceaseless resignification of memory, of the past. In earlier phases of Bulgarian authored music the folkloric heritage was construed as somehow alienated, mainly from the perspective of composers who had been distanced from their "roots." They mined folklore predominantly for building material, for an arsenal of means of expression, for a distinctive sound 
palette, a source of creative ideas and views of the world, or for a specific approach in the search for national identification. Now, however, the player embodies the very idea of folkloric tradition in the contemporary situation. But he is not simply the interpreter of the heritage. He revives his role of a creative subject, which seemed to have been taken away, and himself assumes the fate of his music. The folk player today apparently experiences a new wave of creativity and freedom in reappropriating the "two sides of the coin," as if to revive the syncretism of that artistic behavior which, in jazz as well as in folk, does not divide musicians into composers and performers but turns them into full masters in the process of music-making. 


\section{References}

Gajtandžiev, Gencho. 1990. Populjarnata muzika-pro? contra? [Popular music—pro? contra?]. Sofia: Narodna Prosveta.

_ 2000. Čalgija ne e mrăsna duma! [Chalgija is not a dirty word!] Kultura 37, September 22, 2000: 5.

Kacarova Rajna, Venelin Krăstev, and P. Stajnov, eds. 1967. Enciklopedija na bălgarskata muzikalna kultura. [Encyclopedia of Bulgarian Musical Culture.] Sofia: Institut Za Muzika-BAN.

Kaufman, Dimitrina. 1995. Săvremennite svatbarski orkestri kato "disidentski” formacii. [Contemporary wedding orchestras as "dissident” formations.] Bălgarski Folklore 6: 49-57.

Levy, Claire. 2000. Producirane na poslanija v săvremennata "etničeska" muzika. [Producing meanings in contemporary "ethnic" music.] Bălgarsko muzikoznanie 3: 69-89.

. 2005. Kăm definiraneto na world music. [Toward defining world music.] Bălgarsko muzikoznanie 2: 87-100.

—. 2004. "Who is the 'Other' in the Balkans? Local Ethnic Music as a Different Source of Identities in Bulgaria." In Music, Space and Place, eds. Andy Bennett, Stan Hawkins, and Sheila Whiteley, 4255. London: Ashgate.

Middleton, Richard. 2000. "Musical Belongings." In Western Music and Its Others: Difference, Representation, and Appropriation in Music, eds. Georgina Born and David Hesmondhalgh, 59-85. Los Angeles: University of California Press.

Rice, Timothy. 1994. May It Fill Your Soul: Experiencing Bulgarian Music. Chicago-London: University of Chicago Press.

Sarandilčev, Stefan. 2005. Bălgarskijat folklor izčezva (intervju s prof. Manol Todorov). [Bulgarian folklore is disappearing (an interview with Prof. Manol Todorov).] Starozagorski novini, August 10, 2005: 9.

Slobin, Mark. 1993. Subcultural Sounds: Micromusics of the West. Hanover: Wesleyan University Press.

Zaharieva, Svetlana. 1987. Sviračăt văv folklornata kultura. [The player in folk culture.] Sofia: BAN.

Živkov, Todor Ivanov. 1994. Folklornijat bum. [Folkloric boom.] Folk Panair 2/94: 6. 